ARTICLE

\title{
Ligand engineering to achieve enhanced ratiometric oxygen sensing in a silver cluster-based metal-organic framework
}

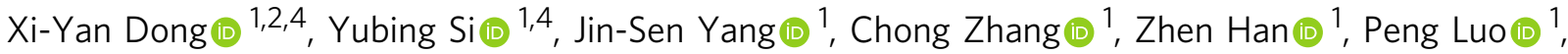 \\ Zhao-Yang Wang (1) ${ }^{1}$, Shuang-Quan Zang (1) ${ }^{1 \times}$ \& Thomas C. W. Mak (1) ${ }^{1,3}$
}

Ratiometric luminescent oxygen sensing based on dual fluorescence and phosphorescence emission in a single matrix is highly desirable, yet the designed synthesis remains challenging. Silver-chalcogenolate-cluster-based metal-organic frameworks that combine the advantages of silver clusters and metal-organic frameworks have displayed unique luminescent properties. Herein, we rationally introduce $-\mathrm{NH}_{2}$ groups on the linkers of a silver-chalcogenolatecluster-based metal-organic framework $\left(\mathrm{Ag}_{12} \mathrm{bpy}-\mathrm{NH}_{2}\right)$ to tune the intersystem crossing, achieving a dual fluorescence-phosphorescence emission from the same linker chromophore. The blue fluorescence component has a 100-nm gap in wavelength and 8,500,000-fold difference in lifetime relative to a yellow phosphorescence component. $\mathrm{Ag}_{12}$ bpy- $\mathrm{NH}_{2}$ quantifies oxygen during hypoxia with the limit of detection of as low as $0.1 \mathrm{ppm}$ and $0.3 \mathrm{~s}$ response time, which is visualized by the naked eye. Our work shows that metal clusterbased MOFs have great potential in luminescent sensing, and the longer-lived chargeseparated states could find more photofunctional applications in solar energy transformation and photocatalysis.

\footnotetext{
${ }^{1}$ Green Catalysis Center, and College of Chemistry, Zhengzhou University, 450001 Zhengzhou, China. ${ }^{2}$ College of Chemistry and Chemical Engineering, Henan Polytechnic University, 454003 Jiaozuo, China. ${ }^{3}$ Department of Chemistry, The Chinese University of Hong Kong, Shatin, New Territories, Hong Kong SAR, China. ${ }^{4}$ These authors contributed equally: Xi-Yan Dong, Yubing Si. ${ }^{凶}$ email: zangsqzg@zzu.edu.cn
} 
O xygen quantification during hypoxia is essential in many fields of science and technology ${ }^{1-3}$, and luminescent $\mathrm{O}_{2}$ sensing has unique advantages, including full reversibility and a good precision and accuracy ${ }^{2,3}$. Commonly, the phosphorescence $(\mathrm{Ph})$ emission intensity and lifetime are easily quenched to a certain extent by triplet oxygen, which becomes the basis of luminescent sensors used to detect molecular oxygen (Fig. 1a $)^{2-7}$. However, it remains challenging to obtain an ultrahigh sensitivity with minimum system error and to detect trace amounts of $\mathrm{O}_{2}$. Scientists are pursuing self-calibrating ratiometric fluorescence $(\mathrm{Fl})$-phosphorescence $(\mathrm{Ph})$ dual emission in a single luminescent matrix ${ }^{8-12}$ with a longer-lived $\mathrm{Ph}$ component ${ }^{13}$ (Fig. 1b), which can not only avoid the errors that are induced by the stoichiometric imbalance of the different emitting centers but also exhibit easily perceived color changes for rapid visual sensing (Fig. 1b). However, thus far, designing such integrated luminophores has achieved limited success for the following reasons: first, achieving balanced $\mathrm{Fl}$ and $\mathrm{Ph}$ intensities originating from the same luminophore is challenging for a ratiometric $\mathrm{O}_{2}$ sensor because, as stated by Kasha's rule, photon emissions occur from only the lowest excited state ${ }^{14}$; second, phosphors that have both long-lived $\mathrm{Ph}$ (over milliseconds) and a high quantum yield (QY) at room temperature are difficult to prepare due to the intrinsic competition between the $\mathrm{Ph}$ lifetime and efficiency ${ }^{15}$; third, this type of luminophore must have a high oxygen permeability for free gas diffusion ${ }^{2-8}$.

Metal-organic frameworks (MOFs) feature flexible secondarybuilding units (SBUs) and infinite tunable organic linkers, as well as abundant and distinctive pores or channels, and hence have shown great potential for separation and sensing ${ }^{8-11,16-32}$. Traditionally, dual emission in MOFs is mostly achieved with lanthanide ion or luminescent linker on a host MOF framework as one emissive center and a post-introduced luminescent species including lanthanide ion, dye or carbon dot as another emissive center, which make it difficult to realize ultrasensitive and ratiometric detection towards oxygen gas ${ }^{11}$. Silver- chalcogenolate-cluster-based metal-organic frameworks (SCCMOFs $)^{33-38}$, in which each SBU consists of tens of silver and chalcogen atoms, have become a new member of the MOF family. SCC-MOFs combine the advantages of silver clusters ${ }^{39-43}$ and MOFs ${ }^{8-11,16-32}$; SCC-MOFs have shown remarkably improved luminescent properties relative to discrete silver clusters and unique excellent luminescent responses for sensing gases and volatile organic compounds (VOCs) ${ }^{33-37}$. We previously reported a SCC-MOF, that is, $\mathrm{Ag}_{12} \mathrm{bpy}^{33},\left(\left[\mathrm{Ag}_{12}\left(\mathrm{~S}^{\mathrm{t} B u}\right)_{8}\left(\mathrm{CF}_{3} \mathrm{COO}\right)_{4}(\mathrm{~b}-\right.\right.$ py $\left.)_{4}\right]_{n}$, bpy $=4,4^{\prime}$-bipyridine), whose single green $\mathrm{Ph}$ is sensitive to oxygen (Fig. 1c). We hypothesize that, according to the interligand trans-metallic charge-transfer (ITCT) emission mechanism of $\mathrm{Ag}_{12} \mathrm{bpy}^{33,36}$, the additional introduction of the organic ligand-centered $\mathrm{Fl}$ emission can achieve dual $\mathrm{Fl}-\mathrm{Ph}$ emission centers in the host framework of a SCC-MOF, whose $\mathrm{Ph}$ component is supposed to be sensitive to oxygen; the functional modification of the MOF linker can modulate the $\mathrm{Ph}$ properties by changing the intersystem crossing (ISC) efficiency; thus, ratiometric oxygen sensing could be achieved in a SCC-MOF with a higher sensitivity.

Here, we first modified the bpy linkers using amino groups bearing lone-pair electrons, i.e., a blue emitting 3-amino- $4,4^{\prime}$ bipyridine $\left(\text { bpy- } \mathrm{NH}_{2}\right)^{31,36}$ moiety, and changed the synthesis method (Supplementary Fig. 1), yielding a new isostructural complex, $\left[\mathrm{Ag}_{12}\left(\mathrm{SBu}^{\mathrm{t}}\right)_{8}\left(\mathrm{CF}_{3} \mathrm{COO}\right)_{4}\left(\mathrm{bpy}-\mathrm{NH}_{2}\right)_{4}\right]_{\mathrm{n}}\left(\mathrm{Ag}_{12} \mathrm{bpy}-\mathrm{NH}_{2}\right)$ (Fig. 1c). The incorporation of amino groups has two significant functions: first, a blue sub-nanosecond Fl component $(0.37 \mathrm{~ns}$ under vacuum) centered at $\sim 456 \mathrm{~nm}$ (Figs. 1c and 2), in addition to a yellow $\mathrm{Ph}$ component at $556 \mathrm{~nm}$, has been achieved; second, incorporating amino groups strongly triggers spin-orbit coupling (SOC) and increases the rate of ISC to boost triplet excitons, thus prolonging the lifetime of the $\mathrm{Ph}$ component by $\sim 15,000$-fold, from submicroseconds $(0.2 \mu \mathrm{s})$ to milliseconds $(3.12 \mathrm{~ms})$, which occurs concomitantly with an increase in the QY from 12.1 to $14.6 \%$ under vacuum. Thus, the large gap of $\sim 100 \mathrm{~nm}$ between the emission wavelengths and the increased lifetime difference
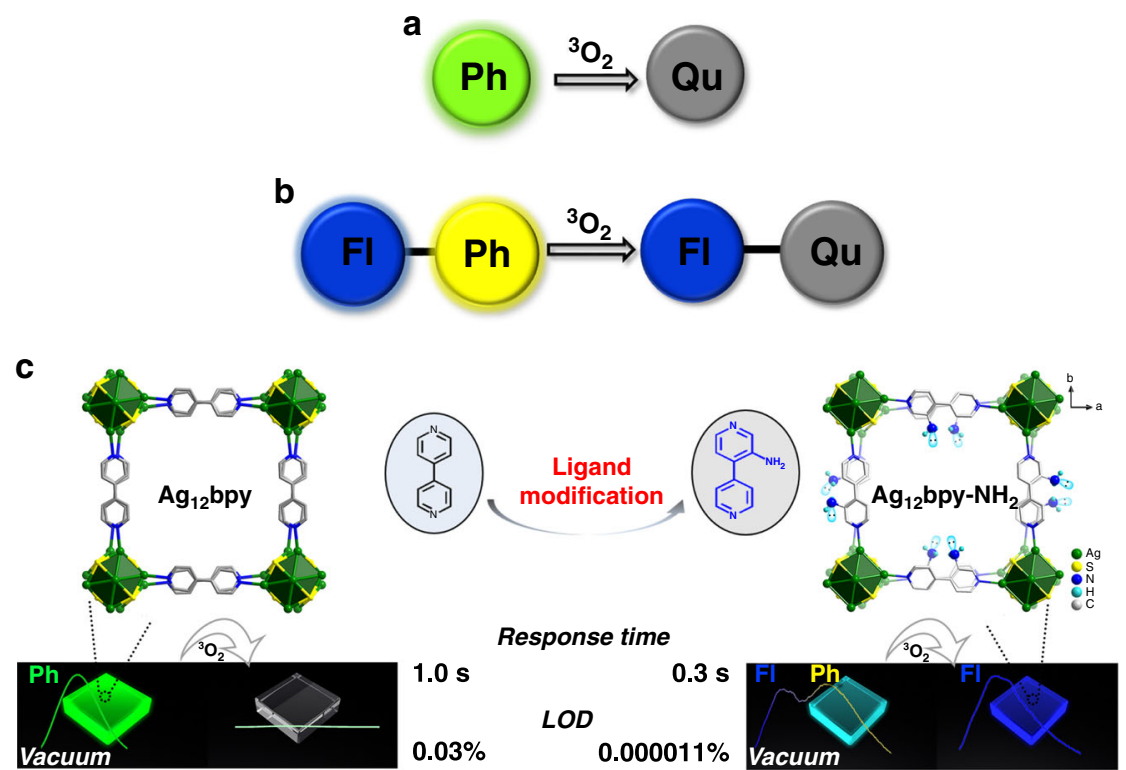

Fig. 1 Schematic luminescent oxygen sensing and ligand modification of SCC-MOFs. Schematic of oxygen quenching sensing based on a single Ph emission and $\mathbf{b}$ dual Fl-Ph emissions. $\mathrm{Fl}=$ Fluorescence, $\mathrm{Ph}=$ Phosphorescence, $\mathrm{Qu}=$ Quenched. Each colored circle represents an emissive center. c Schematic of $\mathrm{Ag}_{12}$ bpy crystals emitting a single green color under vacuum that is quenched by oxygen with a response time of approximately $1.0 \mathrm{~s}$ and an LOD of $0.03 \%$; the isostructural $\mathrm{Ag}_{12}$ bpy- $\mathrm{NH}_{2}$ crystal modified with $-\mathrm{NH}_{2}$ groups on the bpy linkers emits nearly a different cyan color that is composed of a blue $\mathrm{Fl}$ and a yellow $\mathrm{Ph}$ component under a certain vacuum, but only emits blue $\mathrm{Fl}$ under oxygen conditions. Note: the color emitted by $\mathrm{Ag}_{12} \mathrm{bpy}-\mathrm{NH}_{2}$ is variable under different vacuum conditions (see the main text). When using $\mathrm{Ag}_{12} \mathrm{bpy}-\mathrm{NH}_{2}$ as a ratiometric oxygen sensor, the response time decreased to $0.3 \mathrm{~s}$ and the LOD dropped to $0.000011 \%$. 

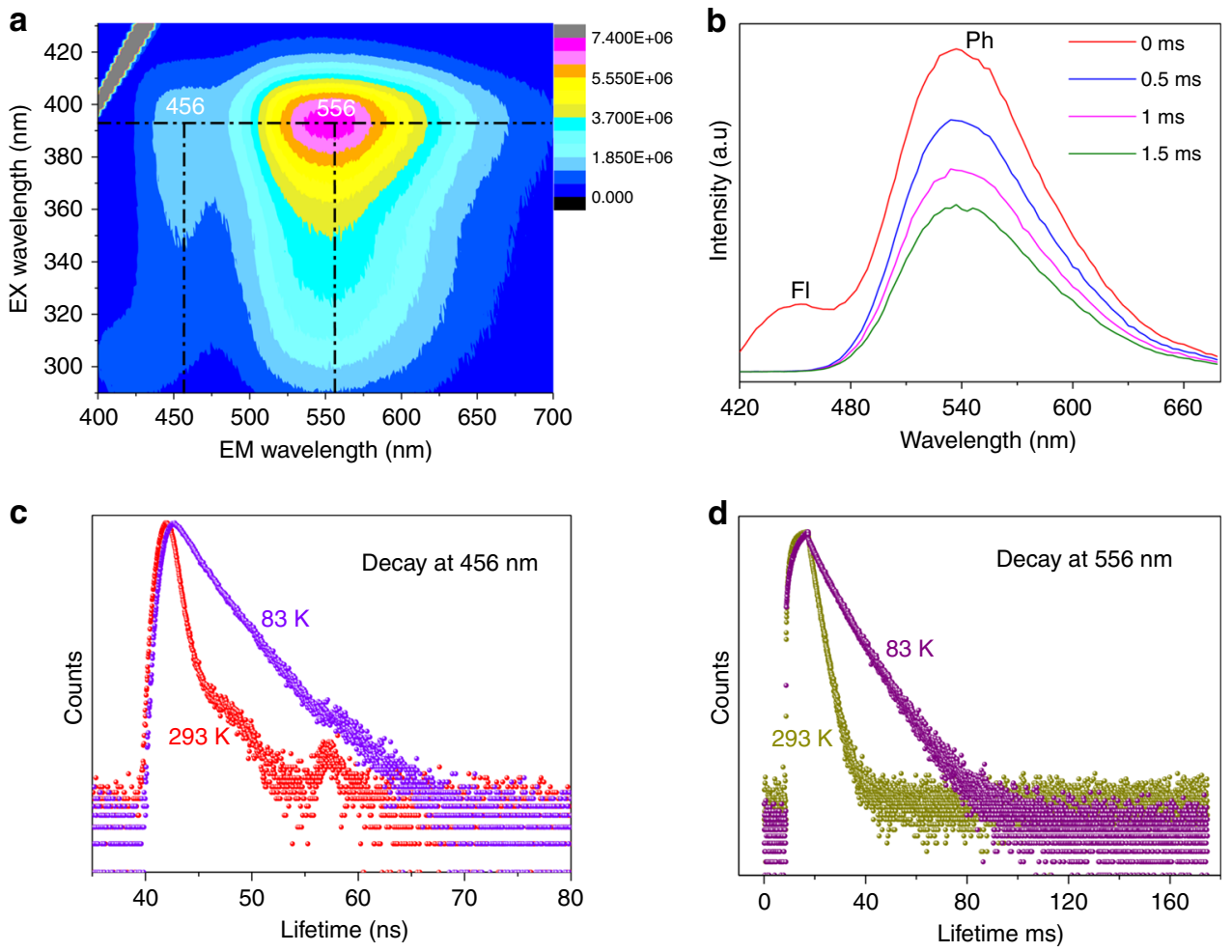

Fig. 2 Photoluminescence properties of $\mathbf{A g}_{\mathbf{1 2}} \mathbf{b p y}-\mathbf{N H}_{\mathbf{2}}$. a The three-dimensional excitation-emission matrix (3D-EEM) spectra of $A g_{12} b p y-N H_{2}$ under a vacuum at room temperature. The two emission centers are located at $\sim 456$ and $556 \mathrm{~nm}$. b Prompt ( $0 \mathrm{~ms})$ and time-delayed $(0.5,1,1.5 \mathrm{~ms})$ emission of solid-state $\mathrm{Ag}_{12}$ bpy- $\mathrm{NH}_{2}$ at room temperature under a vacuum. c Time-resolved $\mathrm{Fl}(456 \mathrm{~nm})$ and $\mathbf{d} \mathrm{Ph}(556 \mathrm{~nm})$ decay traces of $\mathrm{Ag}_{12} \mathrm{bpy}-\mathrm{NH}_{2}$ under a vacuum at 293 and $83 \mathrm{~K}$.

( $8.5 \times 10^{6}$ times) of the $\mathrm{Ph}$ and Fl bands, combined with the highly oxygen-permeable framework structure, enable $\mathrm{Ag}_{12}$ bpy$\mathrm{NH}_{2}$ to function as a single-component $\mathrm{Fl}-\mathrm{Ph}$ ratiometric sensor for molecular oxygen in which ultrafast responses towards trace oxygen gas are achieved in $0.3 \mathrm{~s}$, and the limit of detection (LOD) is as low as $0.1 \mathrm{ppm}$; this response can be visualized by variations in the color, which is dependent on the $\mathrm{O}_{2}$ concentration below $20 \mathrm{ppm}$. To the best of our knowledge, $\mathrm{Ag}_{12}$ bpy- $\mathrm{NH}_{2}$ is the first report of a Fl-Ph dual-emissive MOF that has a record-breaking LOD and response speed ${ }^{8-10,19-25}$. By the further introduction of bulk $-\mathrm{CH}_{3}$ groups on the partial bpy linkers, which interferes with the oxygen collision dynamics, we then prepared another isostructural mixed-linker $\mathrm{Ag}_{12}$ bpy- $\mathrm{NH}_{2} / \mathrm{CH}_{3}$, which extended the ratiometric sensing range. Such long-lived metal-cluster ensembles are promising materials for sensing, photocatalysis, sensitization of electrochemical solar cells, and solar-energyharvesting applications.

\section{Results}

Structure and photoluminescence of $\mathbf{A g}_{12}$ bpy- $\mathbf{N H}_{2}$. Compared to bpy, bpy- $\mathrm{NH}_{2}$ has an unchanged length and unaltered connectivity (Fig. 1c); however, introducing an amino group at the 3position of bpy greatly alters the reaction conditions: the synthesis method used for the $\mathrm{Ag}_{12}$ bpy structures that are synthesized in mixed $\mathrm{CH}_{3} \mathrm{CN}$ and $\mathrm{C}_{2} \mathrm{H}_{5} \mathrm{OH}$ is no longer applicable for $\mathrm{Ag}_{12}$ bpy$\mathrm{NH}_{2}$. After sustained attempts, isomorphous single crystals of $\mathrm{Ag}_{12}$ bpy- $\mathrm{NH}_{2}$ were prepared by the reaction of $\mathrm{AgS}^{t} \mathrm{Bu}$, $\mathrm{CF}_{3} \mathrm{COOAg}$ and bpy- $\mathrm{NH}_{2}$ in a mixed solvent of $\mathrm{NH}_{4} \mathrm{OH}$ and $\mathrm{CH}_{2} \mathrm{Cl}_{2}$ (Supplementary Fig. 1), suggesting that the used solvents play key roles in the structure of SCC-MOFs. The single-crystal $\mathrm{X}$-ray diffraction (SCXRD) analysis revealed that $\mathrm{Ag}_{12}$ bpy- $\mathrm{NH}_{2}$ and $\mathrm{Ag}_{12}$ bpy belong to the same tetragonal space group (No. 121) and have identical silver cluster subunits, and every $\left(-\mathrm{S}^{t} \mathrm{Bu}\right.$,
$-\mathrm{OOCCF}_{3}$ ) ligand and $\mathrm{N}$-containing linker have identical ligand coordination modes (Fig. 1c and Supplementary Figs. 2 and 3). The phase purity and chemical formula of $\mathrm{Ag}_{12}$ bpy- $\mathrm{NH}_{2}$ were further verified by elemental analysis, powder X-ray diffraction (PXRD) and thermogravimetric analysis (TGA) (Supplementary Figs. 4 and 5). The amino groups anchored on the linker slightly decrease the pore void space from $21.6 \%$ for $\mathrm{Ag}_{12}$ bpy to $17.5 \%$ for $\mathrm{Ag}_{12} \mathrm{bpy}-\mathrm{NH}_{2}$, as calculated from the X-ray structural data obtained by PLATON (see Methods) and verified by the measurement of the $77 \mathrm{~K} \mathrm{~N}_{2}$ sorption isotherm (Supplementary Fig. 6). Compared to that of $\mathrm{Ag}_{12} \mathrm{bpy}$, the UV-vis absorption intensity of $\mathrm{Ag}_{12}$ bpy- $\mathrm{NH}_{2}$ obviously increased before $600 \mathrm{~nm}$ and redshifted, extending to $680 \mathrm{~nm}$ (Supplementary Fig. 7). The enhancement before $450 \mathrm{~nm}$ suggests that new $\left(n, \pi^{*}\right)$ transitions possibly occurred because of the introduction of the $-\mathrm{NH}_{2}$ group with a lone-pair on the pyridine ring (Fig. 1c, Supplementary Figs. 8 and 9).

The crystals of $\mathrm{Ag}_{12}$ bpy- $\mathrm{NH}_{2}$ exhibit a blue emission in air and in solution not degassed by $\mathrm{N}_{2}$, which is similar to the blue Fl color of the pure bpy- $\mathrm{NH}_{2}$ linker ${ }^{36}$ in the solid state with a lifetime of approximately $3.59 \mathrm{~ns}$ (Table 1 and Supplementary Figs. 10-12). In contrast, amino-free $\mathrm{Ag}_{12}$ bpy exhibits color-variable $\mathrm{Ph}$ in various organic solvents ${ }^{33}$. These observations implied that the $\mathrm{Ph}$ component of $\mathrm{Ag}_{12}$ bpy- $\mathrm{NH}_{2}$ is likely to be much more sensitive to oxygen in solution than $\mathrm{Ag}_{12}$ bpy. To validate this hypothesis, we subsequently measured the luminescence properties of $\mathrm{Ag}_{12} \mathrm{bpy}$ $\mathrm{NH}_{2}$ under a high vacuum at room temperature, which resulted in highly separated dual emissions (Fig. 2a, b and Table 1) upon excitation with a $370 \mathrm{~nm}$ UV light. One emission is the ligandbased fluorescence emission centered at $\sim 456 \mathrm{~nm}$, which has a lifetime of $0.37 \mathrm{~ns}$ at room temperature and $2.48 \mathrm{~ns}$ at $83 \mathrm{~K}$ (Fig. 2c); this emission lifetime of $0.37 \mathrm{~ns}$ is only one-tenth the lifetime of the solid-state bpy- $\mathrm{NH}_{2}$ ligand (3.59 ns, Table 1 and 
Table 1 Luminescent properties of the compounds.

\begin{tabular}{|c|c|c|c|c|c|c|}
\hline Compound & \multicolumn{3}{|c|}{ Fluorescence } & \multicolumn{3}{|c|}{ Phosphorescence } \\
\hline bpy-NH${ }_{2}$ & 420 & 3.59 & 30.56 & No & No & No \\
\hline $\mathrm{Ag}_{12}$ bpy- $\mathrm{NH}_{2}$ & 456 & 0.37 & 2.54 & 556 & 3.12 & 14.62 \\
\hline $\mathrm{Ag}_{12}$ bpy- $\mathrm{CH}_{3}$ & No & No & No & 500 & $6.8 \times 10^{-5}$ & 3.06 \\
\hline $\mathrm{Ag}_{12}$ bpy-F & No & No & No & 530 & $3.5 \times 10^{-4}$ & 21.80 \\
\hline
\end{tabular}

Supplementary Fig. 11); the Fl QY is significantly reduced from 30.56 to $2.54 \%$, and the Fl peak is also redshifted to $456 \mathrm{~nm}$ compared to the Fl peak of solid-state bpy- $\mathrm{NH}_{2}(420 \mathrm{~nm})$ due to metal coordination (Supplementary Fig. 10). Another emission is an outstanding yellow $\mathrm{Ph}$ emission located at $556 \mathrm{~nm}$, with emission lifetimes of $3.12 \mathrm{~ms}$ at $293 \mathrm{~K}$ and $10.55 \mathrm{~ms}$ at $83 \mathrm{~K}$ (Fig. 2d), which is an increase of 15,000 times compared to the room-temperature $\mathrm{Ph}$ lifetime of $200 \mathrm{~ns}$ observed for unsubstituted $\mathrm{Ag}_{12} \mathrm{bpy}$; in addition, the quantum efficiency increased to $14.62 \%$ compared to the $12.10 \%$ quantum efficiency obtained for unsubstituted $\mathrm{Ag}_{12}$ bpy under vacuum (Table 1). Most importantly, the separation of the $\mathrm{Ph}$ peak at $556 \mathrm{~nm}$ from its $\mathrm{Fl}$ peak at $456 \mathrm{~nm}$ is truly enhanced, and the $\mathrm{Ph}$ intensity greatly surpasses the $\mathrm{Fl}$ intensity under vacuum (Fig. 2b). The significant decrease in the ligand-based $\mathrm{Fl}$ lifetimes of $\mathrm{Ag}_{12} \mathrm{bpy}-\mathrm{NH}_{2}$ from 3.59 to $0.37 \mathrm{~ns}$, which is accompanied by a considerable increase in the $\mathrm{Ph}$ lifetime from $0.2 \mu$ s to $3.12 \mathrm{~ms}$ (Table 1 ), suggested the occurrence of an efficient ISC process from the lowest singlet to the lowest triplet excited states (vide infra). The 15,000-fold enhancement in the $\mathrm{Ph}$ lifetime is an unprecedented phenomenon among luminescent MOFs $^{19-28,33-38}$ and metal clusters ${ }^{39-43}$, even in metal-containing phosphors ${ }^{12,13,44-46}$, which means that the triplet excited state(s) of $\mathrm{Ag}_{12} \mathrm{bpy}-\mathrm{NH}_{2}$ is capable of responding to oxygen molecules with a sensitivity of one-15,000th of the original sensitivity of unsubstituted $\mathrm{Ag}_{12}$ bpy if one merely considers the lifetime factor. Of course, this also presents a challenge for obtaining precise measurements in the range of hypoxia.

Ratiometric optical oxygen sensing. By balancing the $\mathrm{Fl}$ and $\mathrm{Ph}$ intensities upon excitation at a single wavelength in which the $\mathrm{Ph}$ component has a considerably long decay time $(3.12 \mathrm{~ms})$ and highly separated dual emissions, as well as highly oxygenpermeable channels (Figs. 1, 2 and Table 1), $\mathrm{Ag}_{12}$ bpy- $\mathrm{NH}_{2}$ provides a platform to serve as a ratiometric $\mathrm{O}_{2}$ sensor and is ideal for the characterization of nearly anoxic systems. Because of the ultrasensitive oxygen quenching effect of $\mathrm{Ag}_{12} \mathrm{bpy}-\mathrm{NH}_{2}$, measurements must be carried out in a high vacuum system because an inert atmosphere (less than $10 \mathrm{ppb}$ of oxygen) is very difficult to achieve for standard $\mathrm{O}_{2}$ gas sensing. To overcome the difficulty of the measurement, we used a homemade measurement system in conjunction with a gas absorption analyzer (BEL-max physisorption analyzer) to ensure the control of the ultrahigh vacuum with high precision and a spectrofluorometer (HORIBA FluoroLog-3) that was connected to a gas absorption analyzer (MicrotracBEL Belsorp Max) by an optical fiber. An image of this set up for $\mathrm{O}_{2}$ sensing under an ultrahigh vacuum is shown in Supplementary Fig. 13 with a detailed explanation.

Ratiometric optical oxygen sensing using dual-emitting $\mathrm{Ag}_{12}$ bpy- $\mathrm{NH}_{2}$ was achieved by monitoring the response at different oxygen partial pressures (Fig. 3a, b). Oxygeninsensitive blue Fl served as the 'reference' signal, and oxygen- quenchable $\mathrm{Ph}$ served as the response signal for readout. The ratio of the nearly invariant fluorescence response $\left(\lambda_{\mathrm{Fl}}=456 \mathrm{~nm}\right)$ to the oxygen-dependent $\mathrm{Ph}$ response $\left(\lambda_{\mathrm{Ph}}=556 \mathrm{~nm}\right)$ steadily increased with increasing oxygen levels. Overall, $99.9 \%$ of the phosphorescence response was quenched at a pressure of $44.3 \mathrm{~Pa}$. In the range from vacuum $\left(10^{-3} \mathrm{~Pa}\right)$ to $2.4 \mathrm{~Pa}$, a linear SternVolmer plot $(\mathrm{SVP})^{2,8,33}$ was observed $\left(R^{2}=0.993\right)($ Fig. $3 \mathrm{c})$, and a continuous linear color change from blue to yellow was observed in the CIE coordinate diagram, facilitating the identification of the $\mathrm{O}_{2}$ pressure by the naked eye (Fig. 3d). The calculated SternVolmer constant ${ }^{2,8,33}\left(K_{\mathrm{sv}}\right)$ was $2.25 \mathrm{kPa}^{-1}$, and the LOD at $1 \%$ quenching was $11.4 \mathrm{mPa}$. Beyond this point, the $\mathrm{Fl} / \mathrm{Ph}$ plot continued to increase up to $44.3 \mathrm{~Pa}$, which was nearly equal to ambient levels (that is, $21 \% \mathrm{O}_{2}$ ) (Fig. $3 \mathrm{~b}$ ). Compared to the LOD (32 Pa) of $\mathrm{Ag}_{12} \mathrm{bpy}$, the LOD of $\mathrm{Ag}_{12}$ bpy- $\mathrm{NH}_{2}$ was low (11.4 $\mathrm{mPa}$ ), only $3.56 \times 10^{-6 \%}$ of the original value. To further explore the oxygen sensitivity, quick response and recyclability of this system, we recorded the transient luminescence response curves of the dual-emission peak intensity under alternating air/vacuum conditions at RT (Fig. 3e); the nearly invariant Fl intensity at 456 $\mathrm{nm}$ (blue straight line) and the on-off $\mathrm{Ph}$ intensity with sharp contrast at $556 \mathrm{~nm}$ (black folding line) demonstrated that $\mathrm{Fl}$ is a good reference signal. The air-quenching response time was $0.3 \mathrm{~s}$ (Fig. 3f), which is as fast 3.3 times as that of $\mathrm{Ag}_{12}$ bpy $(\sim 1 \mathrm{~s})^{33}$, and is concomitant with the synchronous visual color change (Fig. $3 \mathrm{~d}$ ). Compared to the $\mathrm{Ph}$ lifetime of $\operatorname{Ag}_{12}$ bpy $(0.2 \mu \mathrm{s})^{33}$, we think that the elongated $\mathrm{Ph}$ lifetime of $\mathrm{Ag}_{12}$ bpy- $\mathrm{NH}_{2}$ of $3.12 \mathrm{~ms}$ mainly contributes to the enhanced sensitivity. The calculated void space of $\mathrm{Ag}_{12}$ bpy- $\mathrm{NH}_{2}$ was $17.5 \%$, which is slightly lower than that of $\mathrm{Ag}_{12}$ bpy (21.6\%), as demonstrated by the $77 \mathrm{~K} \mathrm{~N}_{2}$ absorption isotherm (Supplementary Fig. 6). $\mathrm{Ag}_{12}$ bpy- $\mathrm{NH}_{2}$, with an LOD as low as $0.11 \mathrm{ppm}$, is applicable for nearly anoxic systems with oxygen levels in the range of $0.1-24 \mathrm{ppm}$ and has sensitivities that are orders of magnitude above those of conventional sensing MOFs ${ }^{19-28,33-38}$. Ag 12 bpy- $\mathrm{NH}_{2}$ opens the door to completely new applications for monitoring oxygen in previously inaccessible concentration regions and is likely to become invaluable in diverse fields of science and technology.

Extending the sensing range of $\mathrm{O}_{2}$ by introducing bulky $-\mathrm{CH}_{3}$ groups. Considering the dynamic $\mathrm{O}_{2}$-quenching mechanisms of these $\mathrm{SCC}-\mathrm{MOF}_{\mathrm{S}}$, one can imagine that other factors that affect the oxygen collision process would also tune the sensitivity. Based on this hypothesis, we prepared another isostructural SCC-MOF, $\mathrm{Ag}_{12}$ bpy- $\mathrm{CH}_{3}$ (Fig. $4 \mathrm{a}, \mathrm{b}$ ), where the large methyl group, which contributes minimally to the excited state, is expected to intervene in the collision process (Supplementary Figs. 14-19). In contrast to $\mathrm{Ag}_{12}$ bpy- $\mathrm{NH}_{2}$, an opening effect and desorption lag are observed in the absorption isotherms of $\mathrm{Ag}_{12}$ bpy- $\mathrm{CH}_{3}$ at $77 \mathrm{~K}$ (Fig. 4c), and a decrease in the pore volume also appeared due to the relatively increased size of the $-\mathrm{CH}_{3}$ groups, suggesting that the possible weakly viscous interactions between the host and 

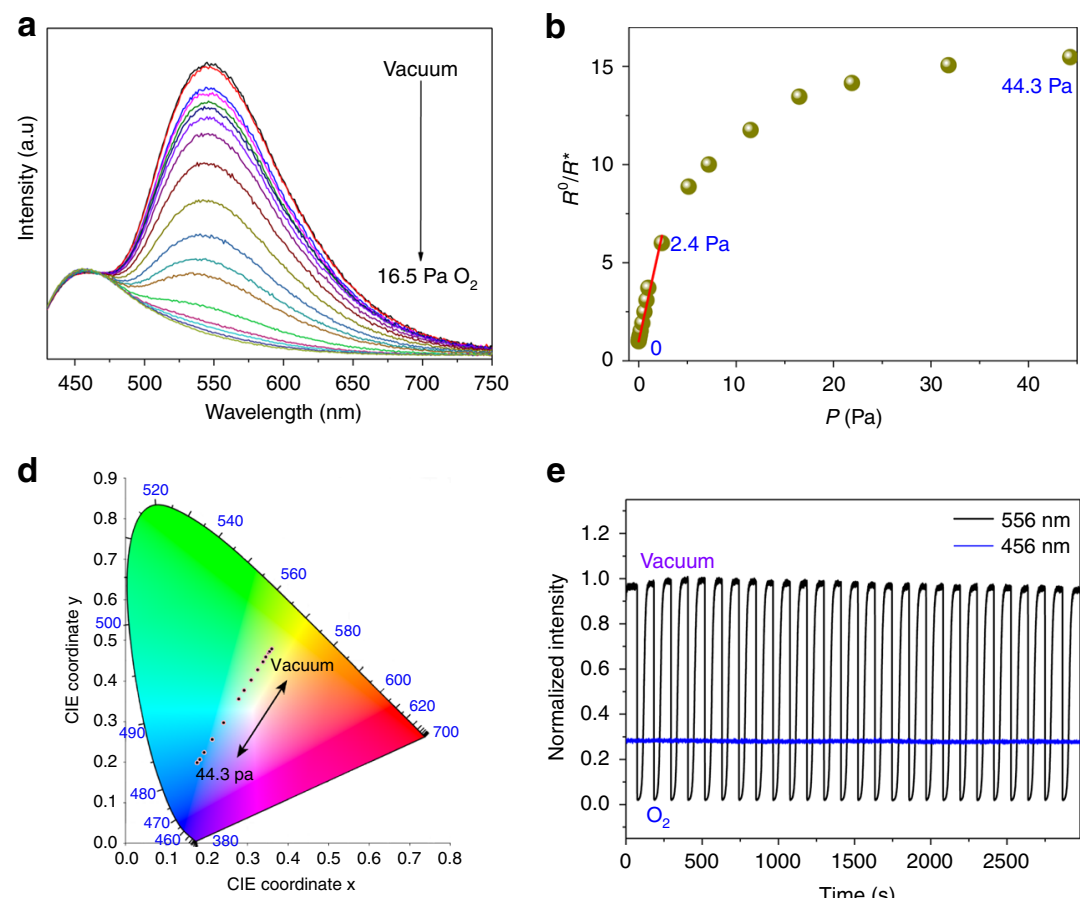

$\mathbf{e}$

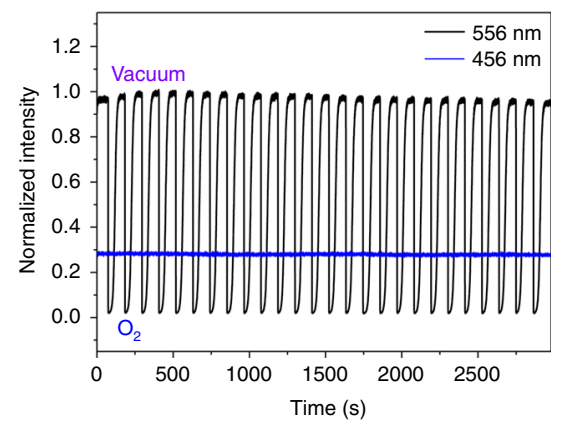

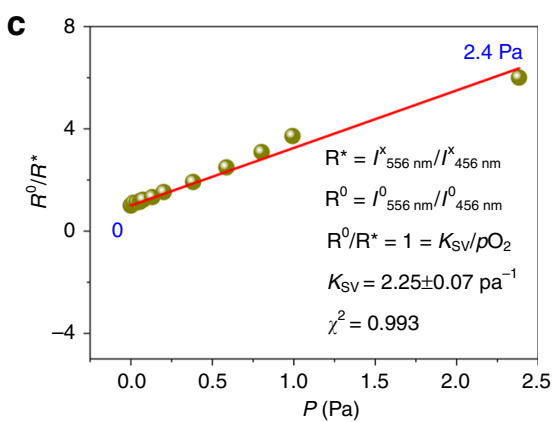

f

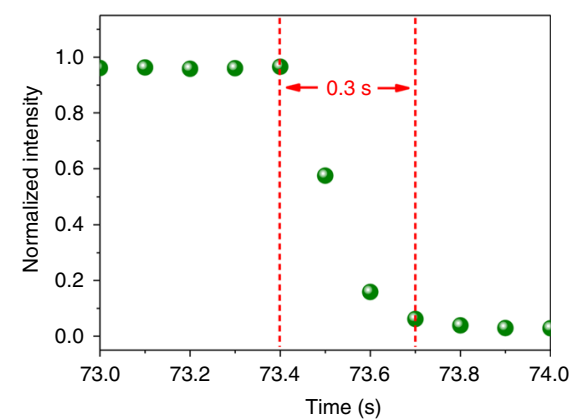

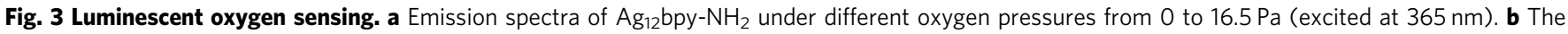

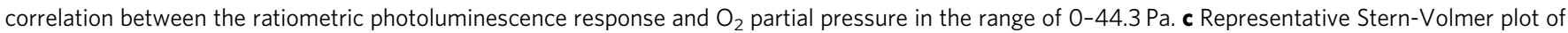
$\mathrm{O}_{2}$ in the range of $0-2.4 \mathrm{~Pa}$. d The emission color-changing range for ratiometric oxygen sensing. e Reversible luminescence cycles of $\mathrm{Ag}_{12}$ bpy- $\mathrm{NH}_{2}$ under alternating exposure to air/vacuum: on-off $\mathrm{Ph}$ (black folding line) and invariant $\mathrm{Fl}$ (blue straight line). $\mathbf{f}$ Enlargement of the response transient curves of $\mathrm{Ag}_{12}$ bpy $-\mathrm{NH}_{2}$ exposed to air. The response time of the air-quenching $\mathrm{Ph}$ component is $\sim 0.3 \mathrm{~s}$ (the response time is defined as the time corresponding to a $90 \%$ decrease in the emission intensity when the gas phase is changed from vacuum to air).

guest hindered gas from freely going in and out. $\mathrm{Ag}_{12} \mathrm{bpy}-\mathrm{CH}_{3}$ merely emits a single green luminescence response (Fig. 4d, Table 1) under vacuum and weakly luminesces in air, implying that the $\mathrm{Ph}$ emission of $\mathrm{Ag}_{12}$ bpy- $\mathrm{CH}_{3}$ is much less sensitive to oxygen than that of $\mathrm{Ag}_{12}$ bpy- $\mathrm{NH}_{2}$. The oxygen-sensing experiments showed that $\mathrm{Ag}_{12}$ bpy- $\mathrm{CH}_{3}$ can work in the range of higher oxygen concentrations $(0.1-21 \%$ in air, Fig. $4 d)$. To further understand the origin of the insensitivity induced by the $-\mathrm{CH}_{3}$ groups, we prepared a molecular oxygen inclusion compound, namely, $\mathrm{Ag}_{12}$ bpy- $\mathrm{CH}_{3} \cdot \mathrm{O}_{2}$, at $80 \mathrm{~K}$ (Fig. 4b); the channels of $\mathrm{Ag}_{12}$ bpy- $\mathrm{CH}_{3} \cdot \mathrm{O}_{2}$ contained the most preferred position of $\mathrm{O}_{2}$ molecules, which had a site occupancy of 0.1 and were the nearby $-\mathrm{CH}_{3}$ groups, and the separation between the $\mathrm{O}_{2}$ and $-\mathrm{CH}_{3}$ groups $(\mathrm{O} \cdots \mathrm{H}=2.29 \AA, \mathrm{O} \cdots \mathrm{C}=2.65 \AA$ ) was much smaller than that between the $\mathrm{O}_{2}$ and bpy moieties (4.05 $\AA$ ) (Supplementary Fig. 20). Considering that the kinetic diameter of $\mathrm{O}_{2}$ is $3.46 \AA^{32}$ and that the $-\mathrm{CH}_{3}$ groups are minimally involved in the excited states, we proposed that $\mathrm{O}_{2}$ molecules have fewer chances to dynamically collide with LUMO localized bpy- $\mathrm{CH}_{3}$ in $\mathrm{Ag}_{12}$ bpy$\mathrm{CH}_{3}$ and can not effectively switch off their emission, resulting in insensitivity. Then, further than that, a mixed-linker crystal of $\mathrm{Ag}_{12}$ bpy- $\mathrm{NH}_{2} / \mathrm{CH}_{3}$ (with a bpy- $\mathrm{NH}_{2}$ :bpy- $\mathrm{CH}_{3}$ ratio of $1: 100$, as determined by ${ }^{1} \mathrm{H}$ NMR, Supplementary Figs. 21 and 22) was prepared and functions in the $\mathrm{O}_{2}$ concentration range of $20 \mathrm{ppm}$ to $0.1 \%$ (Fig. 4 e). The contrasting effect of the $-\mathrm{NH}_{2}$ and $-\mathrm{CH}_{3}$ groups on the oxygen-sensing performance indicate that the proposed dynamic quenching process by oxygen is a photophysical process, during which the interactions between molecular (triplet) oxygen and the excited electronic states of the SCCMOFs are controlled by the emissive lifetime and the permeability or diffusion rate of oxygen. The $-\mathrm{NH}_{2}$ groups, markedly enhanced the sensitivity by generating an oxygen-insensitive reference blue Fl signal and simultaneously elongating the yellow
$\mathrm{Ph}$ component lifetime; while, the $-\mathrm{CH}_{3}$ groups mainly decrease the sensitivity by erecting barriers of $\mathrm{O}_{2}$ diffusion in the channels of the SCC-MOFs. The balance modulation can tune the sensing range of oxygen. Therefore, engineering the ligands on SCCMOFs is deemed to be a powerful method of modulating the remarkable luminescent sensing functionality.

Luminescent properties of isostructural SCC-MOFs with different substituents. To gain further insights into the origin of the dual emission and the long-lived $\mathrm{Ph}$ lifetime of $\mathrm{Ag}_{12}$ bpy- $\mathrm{NH}_{2}$, we compared two additional isostructural crystals, $\mathrm{Ag}_{12} \mathrm{bpy}-\mathrm{CH}_{3}$ containing bpy- $\mathrm{CH}_{3}$ linkers with an electron-donating methyl group and $\mathrm{Ag}_{12}$ bpy- $\mathrm{F}^{36}$ containing 3-fluorine-4,4'-bipyridine (bpy-F) bearing an electron-withdrawing fluoro group (Table 1). Based on the above mentioned experimental results, we have observed that in the absence of an efficient $\mathrm{Fl}$ emission produced by bpy- $\mathrm{CH}_{3}$ and bpy-F, only a single phosphorescence response appears in $\mathrm{Ag}_{12}$ bpy- $\mathrm{CH}_{3}$ and $\mathrm{Ag}_{12}$ bpy-F. Similar to most metalcontaining phosphors involving a $\pi^{*}$-orbital-involved chargetransfer emission ${ }^{12,44,45}$, electron-donating $-\mathrm{CH}_{3}$ groups likely destabilize the $\pi^{*}$ orbital, decrease the lifetime to approximately $68 \mathrm{~ns}$ under vacuum, and cause a blueshift of only $7 \mathrm{~nm}$ under vacuum; however, electron-withdrawing $-F$ groups have the opposite effect and increase the lifetimes (351 $\mathrm{ns}^{36}$, Table 1) and result in a redshift of more than $20 \mathrm{~nm}$. This variation induced by the electron-donating/withdrawing effect still occurred on the same order of magnitude of submicroseconds, indicating that the inherent emissive excited state did not change. In stark contrast, the $\mathrm{Ph}$ component of $\mathrm{Ag}_{12}$ bpy- $\mathrm{NH}_{2}$ unprecedentedly increased drastically by over four orders of magnitude. We proposed that the $-\mathrm{NH}_{2}$ substituent might take part in the emissive triplet state and promote ISC from the singlet to triplet state. The Fl 
a
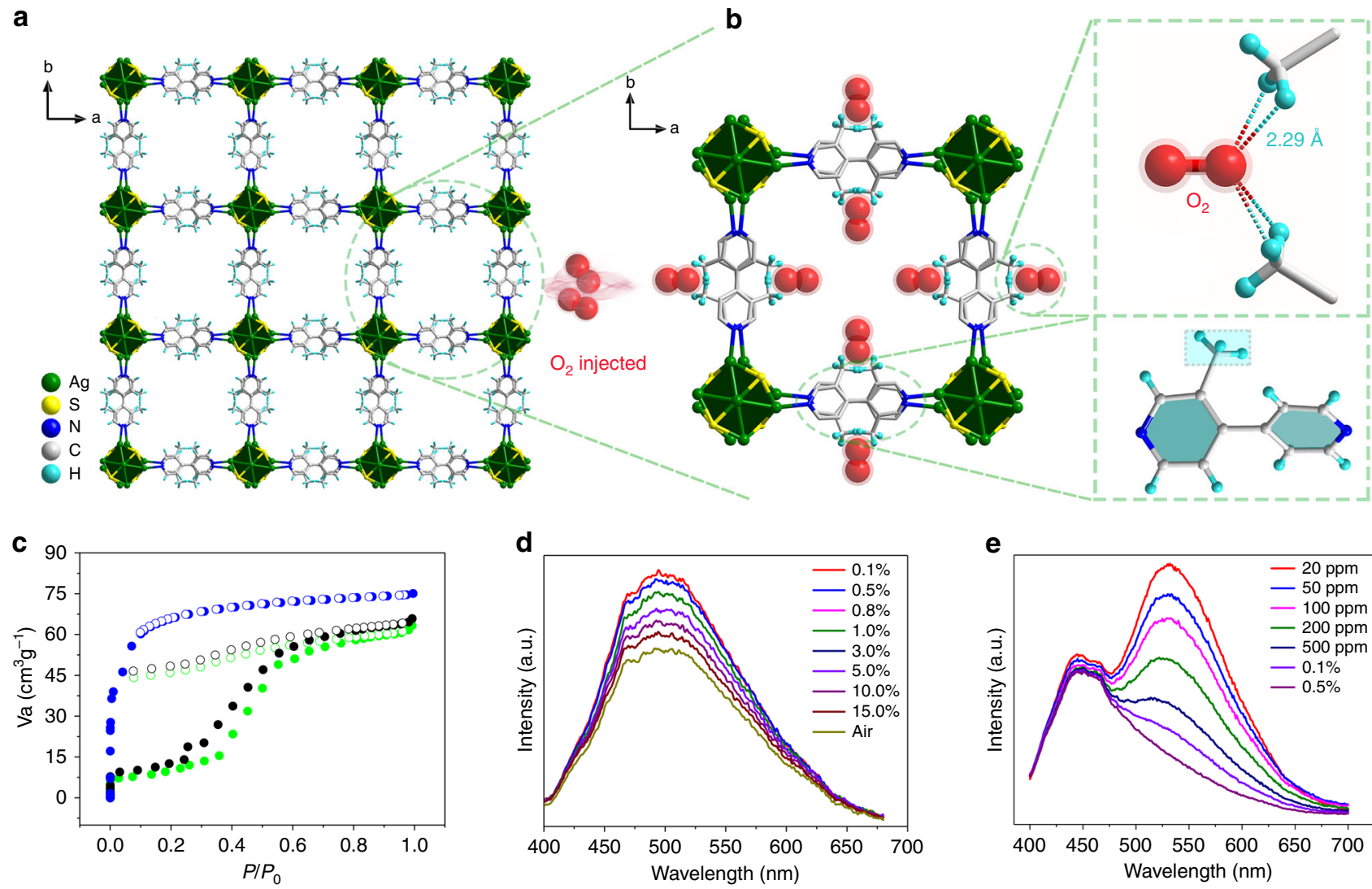

Fig. 4 The oxygen molecule position in $\mathbf{A g}_{\mathbf{1 2}} \mathbf{b p y}-\mathbf{C H}_{\mathbf{3}}$ and the oxygen-sensing performance. a Channels of $\mathrm{Ag}_{12} \mathrm{bpy}-\mathrm{CH}_{3}$ and $\mathbf{b} \mathrm{O}_{2}$-inclusion of $A g_{12}$ bpy$\mathrm{CH}_{3} \cdot \mathrm{O}_{2}$, as viewed along the $\mathrm{c}$-axis. The most preferable positions of the oxygen molecules are displayed. The smallest separation between $\mathrm{O}_{2}$ and the $\mathrm{CH}_{3}$ groups $(\mathrm{O} \cdots \mathrm{H})$ is equal to $2.29 \AA$. Color code: $\mathrm{Ag}$, green; $\mathrm{S}$, yellow; $\mathrm{C}$, gray; $\mathrm{N}$, blue; $\mathrm{H}$, light turquoise; $\mathrm{O}$, red. The $\mathrm{H}$ atoms of bpy and $-{ }^{\mathrm{t}} \mathrm{Bu}$ groups of the host backbone are omitted for clarity. $\mathbf{c} \mathrm{N}_{2}$ adsorption/desorption isotherms of $\mathrm{Ag}_{12}$ bpy- $\mathrm{NH}_{2}$ (blue line), $\mathrm{Ag}_{12} \mathrm{bpy}-\mathrm{CH}_{3}\left(\mathrm{green}\right.$ line) and $\mathrm{Ag}_{12}$ bpy- $\mathrm{NH}_{2} /$ $\mathrm{CH}_{3}$ (1:100) (black line) at $77 \mathrm{~K}$. d Oxygen-dependent emission intensity of $\mathrm{Ag}_{12}$ bpy- $\mathrm{CH}_{3}$ in the range of $0.1 \%$ to ambient air conditions. e Oxygendependent dual-emission intensity of $\mathrm{Ag}_{12}$ bpy $-\mathrm{NH}_{2} / \mathrm{CH}_{3}$ (1:100) in the range of $20 \mathrm{ppm}$ to $0.5 \%$.

component of $\mathrm{Ag}_{12}$ bpy- $\mathrm{NH}_{2}$, with a lifetime of $0.37 \mathrm{~ns}$, possibly originates from the mixed ${ }^{1}\left(n, \pi^{*}\right)$ and ${ }^{1}\left(\pi, \pi^{*}\right)$ excited singlet states; the $\mathrm{Ph}$ component of $\mathrm{Ag}_{12}$ bpy- $\mathrm{NH}_{2}$ with a lifetime of 3.12 $\mathrm{ms}$, might originate from the mixed ${ }^{3}$ ITCT and ${ }^{3}\left(n, \pi^{*}\right)$ triplet states in which the participation of ${ }^{3}\left(n, \pi^{*}\right)$ could facilitate ISC and probably varies the characteristics of the lowest emissive triplet states, eventually leading to a 15,000 -fold elongation of the lifetime and a more than $40-\mathrm{nm}$ redshift. The incomplete electron communication between the two emissive states could result in a Fl-Ph dual emission (Supplementary Fig. 23).

The amino groups modulating the emissive triplet states and prompting ISC. The $\mathrm{Fl}$ energy of the free bpy- $\mathrm{NH}_{2}$ ligand is dependent on the solvent (Supplementary Fig. 10), which is consistent with the charge-transfer (CT) characteristics and further indicates that the emissive singlet state could combine the ${ }^{1}$ $\left(\mathrm{n}, \pi^{*}\right)$ state with the ${ }^{1}\left(\pi, \pi^{*}\right)$ state. In contrast, the $\mathrm{Fl}$ component of $\mathrm{Ag}_{12}$ bpy- $\mathrm{NH}_{2}$ is independent of the solvent (Supplementary Fig. 12); it is likely that the ligand-based ${ }^{1}\left(\pi, \pi^{*}\right)$ state may be the localized excited state at bpy- $\mathrm{NH}_{2}$ linkers of $\mathrm{Ag}_{12}$ bpy- $\mathrm{NH}_{2}$ (Supplementary Fig. 23). From these comparison data, a schematic of the evolving luminescence is presented: the blue Fl component of the ligand, which stems from the emissive singlet state, was considerably decreased by $92.8 \%$, which is calculated from the lifetime. For $\mathrm{Ag}_{12} \mathrm{bpy}$, we previously ascribed the $\mathrm{Ph}$ component to ITCT ( $/ \mathrm{Ag} \rightarrow \mathrm{bpy})^{36}$. Thus, the $\mathrm{Ph}$ component of $\mathrm{Ag}_{12}$ bpy- $\mathrm{NH}_{2}$ from the ${ }^{*}$ ITCT triplet state $\left(\mathrm{S} / \mathrm{Ag} \rightarrow\right.$ bpy- $\left.\mathrm{NH}_{2}\right)$ redshifted to $556 \mathrm{~nm}$, and its intensity increased; the most attractive feature of this system is the increase in the lifetime to the millisecond range. The trend between $\mathrm{Fl}$ and $\mathrm{Ph}$ indicates that (i) the emissive triplet state of $\mathrm{Ag}_{12}$ bpy- $\mathrm{NH}_{2}$ has a lower energy and is relatively stable, and (ii) the charge transfer and energy transfer from the bpy- $\mathrm{NH}_{2}$-based ${ }^{1}\left(\pi, \pi^{*}\right)$-dominated emissive single state to the ${ }^{3}$ ITCT $\left(\mathrm{S} / \mathrm{Ag} \rightarrow \pi^{*}\right.$ of bpy- $\left.\mathrm{NH}_{2}\right)$ triplet state was mixed with a small amount of ${ }^{3}\left(n, \pi^{*}\right)$. Therefore, incorporating the $-\mathrm{NH}_{2}$ group into the bpy linkers significantly changed molecular energy levels (see the calculated molecular orbitals and analysis of $\mathrm{Ag}_{12}$ bpy- $\mathrm{NH}_{2}$ shown in Supplementary Figs. 23-26 and Supplementary Table 1).

Moreover, because the rate constant of the ISC from singlet to triplet excited states is proportional to the square of the SOC constant, we examined 20 of the lowest singlet-triplet transitions by performing calculations for $\mathrm{Ag}_{12} \mathrm{bpy}-\mathrm{NH}_{2}, \mathrm{Ag}_{12} \mathrm{bpy}-$ $\mathrm{CH}_{3}, \mathrm{Ag}_{12}$ bpy-F, and $\mathrm{Ag}_{12}$ bpy (Fig. 5). Considering that spinflipping may be enhanced by the resonance variation with an increased n-value orbital participation ${ }^{47}$, the triplet excited states with a small vertical excitation energy gap $\left(\Delta \mathrm{E}_{\mathrm{S} 1 \mathrm{Tn}}\right.$ less than $0.15 \mathrm{eV}$ ) were included. $\mathrm{Ag}_{12} \mathrm{bpy}-\mathrm{NH}_{2}$ has far more triplet excited states $\left(T_{n}\right)$ close to $S_{1}$ in energy, and the smaller energy gap and higher SOC would well support the efficient ISC process to generate more triplet states with much longer lifetimes. For $\mathrm{Ag}_{12}$ bpy- $\mathrm{NH}_{2}$, the transitions between $S_{1}$ and $\mathrm{T}_{\mathrm{n}}$ are the transitions from locally excited (LE) states ${ }^{1}\left(\pi, \pi^{*}\right)$ to charge-transfer triplet states mixed with ${ }^{3}\left(n, \pi^{*}\right)$ and ${ }^{3}$ ITCT, which would result in the high SOC according to the El-Sayed rules ${ }^{48-50}$. Thus, the participation of the $-\mathrm{NH}_{2}$ units actually 

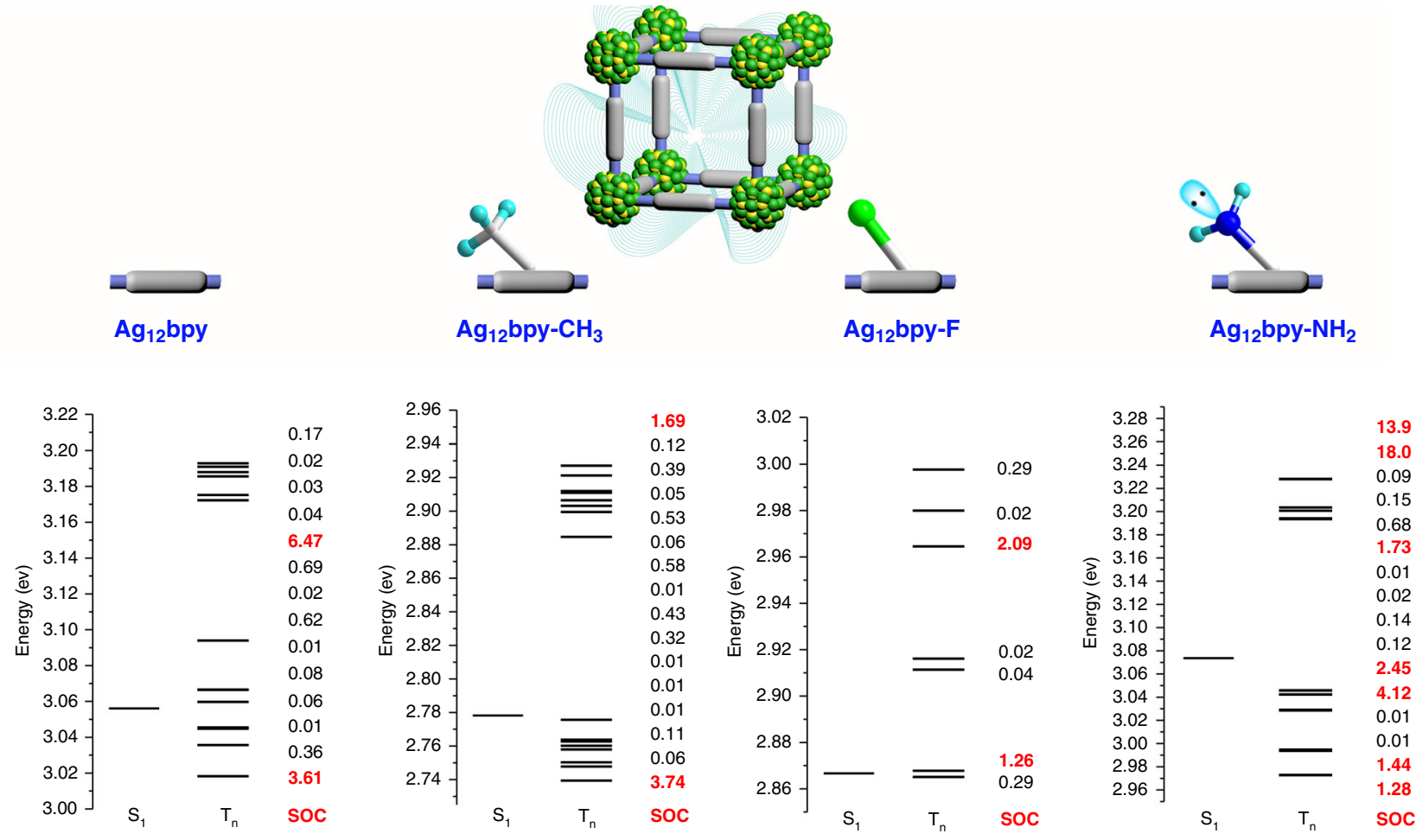

Fig. 5 Energy level diagram and SOC constants. The SOC values are in $\mathrm{cm}^{-1}$, and the high values $\left(>1 \mathrm{~cm}^{-1}\right)$ are in bold red. There are 4, 8,1 , and 10 triplet states that are lower than the corresponding singlet state of the pristine, $-\mathrm{CH}_{3},-\mathrm{F}$, and $-\mathrm{NH}_{2}$ substituted molecules. Considering that the resonance structures may promote $\mathrm{ISC}^{47}$, the higher triplet states with a low energy gap $\left(\Delta \mathrm{E}_{\mathrm{S} 1 \mathrm{Tn}_{\mathrm{n}}}<0.15 \mathrm{eV}\right)$ were displayed.

results in a new facile pathway for the ISC process to occur between $S_{1}$ and $T_{n}$, increasing the effective ISC to achieve an efficient longer-lived $\mathrm{Ph}$ response.

\section{Discussion}

In summary, we have devised a simple yet powerful strategy to tune the delicate balance between the emissive intraligand singlet states and CT triplet states, which enables the observation of dual $\mathrm{Fl}$ and $\mathrm{Ph}$ peaks with a $100-\mathrm{nm}$ separation and an 8,500,000-fold lifetime gap, and have provided the first model of dual Fl-Ph ultrasensitive ratiometric $\mathrm{O}_{2}$ sensing in the range of hypoxia based on a single-component SCC-MOF. The introduced amine groups $\left(-\mathrm{NH}_{2}\right)$ with lone-pair electrons strengthened SOC and facilitated ISC and, henceforth, induced a 15,000-fold enhancement in the Ph lifetime from submicroseconds to milliseconds. Furthermore, using a substituent-mediated strategy $\left(-\mathrm{CH}_{3}\right.$ and mixed $-\mathrm{NH}_{2}$ and $-\mathrm{CH}_{3}$ groups) to interfere with the dynamic quenching process of $\mathrm{O}_{2}$ extends the sensing concentration range. The bright long-lifetime excited states and the homogeneously ordered spatial separation of metal clusters enable these metalcluster ensembles to be used in sensing, imaging, photocatalysis, and solar-energy-harvesting applications.

\section{Methods}

Reagents. All reagents and solvents used were of commercially available reagent grade and used without further purification. $\mathrm{AgS} \mathrm{Bu}^{\mathrm{B}} \mathrm{was}$ prepared from the reaction of molar equivalents of $\mathrm{Ag}_{2} \mathrm{O}$ and $\mathrm{HS}^{\mathrm{t}} \mathrm{Bu}$ in $\mathrm{Et}_{3} \mathrm{~N}$.

Synthesis of bpy- $\mathbf{N H}_{\mathbf{2}}$ and bpy- $\mathbf{C H}_{\mathbf{3}}$. 3-amino-4,4'-bipyridine $\left(\mathrm{bpy}-\mathrm{NH}_{2}\right)$ and 3-methyl-4, $4^{\prime}$-bipyridine (bpy- $\mathrm{CH}_{3}$ ) were prepared from Suzuki coupling of 3-amino-4-chloropyridine or 3-methyl-4-chloropyridine and pyridine-4-boronic $\operatorname{acid}^{31}$.

Preparation of $\mathbf{A g}_{\mathbf{1 2}}$ bpy- $\mathbf{N H}_{\mathbf{2}}$ single crystals. 3-amino-4,4'-bipyridine (bpy- $\mathrm{NH}_{2}$, $10 \mathrm{mg}$ ) and $10 \mu \mathrm{L}$ ammonium hydroxide were added to a solution of $\mathrm{AgSt} B u$
(15 mg), $\mathrm{CF}_{3} \mathrm{COOAg}(6 \mathrm{mg})$ and $\mathrm{CH}_{2} \mathrm{Cl}_{2}(4 \mathrm{~mL})$ under stirring to obtain a clear solution under ambient conditions. The reaction solution was filtered, and the filtrate was slowly evaporated in air to give bulk colourless crystals, which were rinsed with $\mathrm{CH}_{2} \mathrm{Cl}_{2}$, filtered and dried in air to produce $\mathrm{Ag}_{12}$ bpy- $\mathrm{NH}_{2}$ $\left(\mathrm{C}_{80} \mathrm{H}_{108} \mathrm{Ag}_{12} \mathrm{~F}_{12} \mathrm{~N}_{12} \mathrm{O}_{8} \mathrm{~S}_{8}\right)$ in $\sim 30 \%$ yield based on Ag. Elemental analysis (calculated): C 30.55, H 3.46, N 5.34, S, 8.16\%; Found: C 30.42, H 3.53, N 5.41, S, 8.09\%.

Preparation of $\mathbf{A g}_{\mathbf{1 2}}$ bpy- $\mathbf{C H}_{\mathbf{3}}$ single crystals. Single crystals of $\mathrm{Ag}_{12}$ bpy- $\mathrm{CH}_{3}$ were prepared in a manner like the preparation of $\mathrm{Ag}_{12} \mathrm{bpy}-\mathrm{NH}_{2}$, except bpy- $\mathrm{NH}_{2}$ was replaced by bpy- $\mathrm{CH}_{3}$; a yield of $\sim 55 \%$ was achieved based on $\mathrm{Ag}$. $\mathrm{Ag}_{12} \mathrm{bpy}-\mathrm{CH}_{3}$ $\left(\mathrm{C}_{84} \mathrm{H}_{112} \mathrm{Ag}_{12} \mathrm{~F}_{12} \mathrm{~N}_{8} \mathrm{O}_{8} \mathrm{~S}_{8}\right)$ Elemental analysis (calculated): C 32.12, H 3.59, N 3.57, S, 8.17\%; Found: C 32.18, H 3.64, N 3.56, S, 8.11\%.

Preparation of $\mathbf{A g} \mathbf{g}_{\mathbf{1 2}}$ bpy- $\mathbf{C H}_{\mathbf{3}} \cdot \mathbf{O}_{\mathbf{2}}$ single crystals. A single crystal of $\mathrm{Ag}_{12}$ bpy- $\mathrm{CH}_{3}$ was evacuated to a pressure of $10^{-3}-10^{-4} \mathrm{~Pa}$. Next, pure pressurized $\mathrm{O}_{2}$ was backfilled at $77 \mathrm{~K}$ through the open end of the capillary until the pressure reached $30 \mathrm{kPa}$. Subsequently, the open end was sealed in situ to maintain the crystal under high pure $\mathrm{O}_{2}$ pressure surroundings, producing $\mathrm{Ag}_{12}$ bpy- $\mathrm{CH}_{3} \cdot \mathrm{O}_{2}$, which was subjected to SCXRD analysis at $80 \mathrm{~K}$.

Preparation of $\mathbf{A g}_{\mathbf{1 2}}$ bpy- $\mathbf{N} \mathbf{H}_{\mathbf{2}} / \mathbf{C H}_{\mathbf{3}}$ crystals. Crystals of $\mathrm{Ag}_{12}$ bpy- $\mathrm{NH}_{2} / \mathrm{CH}_{3}$ were prepared similar to $\mathrm{Ag}_{12}$ bpy- $\mathrm{NH}_{2}$, except the mixture of bpy- $\mathrm{NH}_{2}$ and bpy- $\mathrm{CH}_{3}$ were added into the reaction solution simultaneously. Different ratios of bpy- $\mathrm{NH}_{2}$ to bpy- $\mathrm{CH}_{3}$ were attempted according to the relative intensity of two emission peaks. The optimized ratio of bpy- $\mathrm{NH}_{2}:$ bpy- $\mathrm{CH}_{3}=1: 100$ was determined by ${ }^{1} \mathrm{H}$ NMR (Supplementary Fig. 22).

Crystallographic data collection and refinement of the structure. SCXRD measurements of $\mathrm{Ag}_{12}$ bpy- $\mathrm{NH}_{2}$ and $\mathrm{Ag}_{12}$ bpy-CH $\mathrm{CH}_{3}$ were performed at $150 \mathrm{~K}$ and measurements of $\mathrm{Ag}_{12}$ bpy- $\mathrm{CH}_{3} \cdot \mathrm{O}_{2}$ were performed at $80 \mathrm{~K}$ on a Rigaku XtaLAB Pro diffractometers with $\mathrm{Cu}-\mathrm{Ka}$ radiation $(\lambda=1.54184 \AA)$. Data collection and reduction were performed using the program CrysAlisPro ${ }^{51,52}$. All the structures were solved with direct methods (SHELXS) ${ }^{53}$ and refined by full-matrix least squares on $F^{2}$ using OLEX2 ${ }^{54}$, which utilizes the SHELXL-2015 module ${ }^{55}$. All atoms were refined anisotropically, and hydrogen atoms were placed in calculated positions with idealized geometries and assigned fixed isotropic displacement parameters. Detailed information about the X-ray crystal data, intensity collection procedure and refinement results for $\mathrm{Ag}_{12}$ bpy- $\mathrm{NH}_{2}, \mathrm{Ag}_{12}$ bpy- $\mathrm{CH}_{3}$, and $\mathrm{Ag}_{12}$ bpy$\mathrm{CH}_{3} \cdot \mathrm{O}_{2}$ is summarized in Supplementary Table 2 . 
Calculation of void space. The fraction of void space was calculated from the Xray structural data of $\mathrm{Ag}_{12}$ bpy- $\mathrm{NH}_{2}$ by PLATON/VOID: The unit cell was filled with the atoms from the structural model, and each specific atom was assigned its respective van der Waals radius. A grid search generated a list of grid points with a minimum distance of $1.2 \AA$ from the nearest van der Waals surface. This list of grid points was then used to produce a new list of grid points that makes up the solvent accessible areas. For the sets of grid points, the centre of gravity and volume of the void were calculated. The overall solvent accessible volume was calculated, along with the volume and centre of gravity of individual 'voids'.

Quantum chemical calculations. Density functional theory (DFT) calculations were performed in Gaussian $16^{56}$ using the PBE0 hybrid functional (mixes the Perdew-Burke-Ernzerhof ${ }^{57}$ and Hartree-Fock exchange energy in a set 3:1 ratio) with the 6-31 G* basis set for $\mathrm{H}, \mathrm{B}, \mathrm{C}, \mathrm{N}, \mathrm{O}, \mathrm{F}$, and $\mathrm{S}$ atoms $\mathrm{s}^{58,59}$ and LanL2DZ effective core potentials for $\mathrm{Ag}$ atoms ${ }^{60,61}$. The single-crystal structure was chosen as the initial guess for ground-state geometry optimization, and all reported stationary points were verified as true minima by the absence of negative eigenvalues in the vibrational frequency analysis. The calculated absorption spectra were obtained from GaussSum 2.162. Hirshfeld population analysis was conducted by Multiwfn $3.4^{63}$. Considering the ISC occurs at the excited states, the timedependent DFT calculations were further carried out with the B3LYP/def2-SVP level based on the optimized structures. The spin-orbit coupling (SOC) matrix elements for the four systems were computed using the spin-orbit mean-field (SOMF) approach in the B3LYP/def2-SVP level in the ORCA 4.1.2 package64 The resolution of the identity (RI) approximation was used during the SOC calculations with the RIJONX flag to speed up the self-consistent field (SCF) convergence during each step. The auxiliary basis sets used with the RI approximation are built automatically by ORCA ${ }^{65,66}$. Over 3000 basis functions were included to create the molecular orbitals, and a typical calculation of 20 singlet and 20 triplet roots were calculated considering the molecules are extremely large ( $>300$ atoms for each).

Luminescence measurements. All solid-state $\mathrm{Ag}_{12}$ bpy- $\mathrm{NH}_{2}, \mathrm{Ag}_{12}$ bpy- $\mathrm{CH}_{3}$, and $\mathrm{Ag}_{12}$ bpy- $\mathrm{NH}_{2} / \mathrm{CH}_{3}$ (1:100) samples were evacuated before the collection of luminescence spectra, in addition to solvent-dependent luminescence measurements in Supplementary Fig. 12. Steady-state photoluminescence (PL) spectroscopy, threedimensional excitation-emission matrix (3D-EEM) luminescence spectroscopy, and emission decay spectroscopy were performed on a HORIBA instrument.

Oxygen-sensing measurements. The $\mathrm{Ag}_{12}$ bpy- $\mathrm{NH}_{2}$ samples were placed in a holder in a gas absorption analyser (BEL-max physisorption analyser, MicrotracBEL Belsorp Max with an ultimate vacuum of $6.7 \times 10^{-7} \mathrm{~Pa}$ ) to precisely control the $\mathrm{O}_{2}$ pressure at nearly anaerobic conditions, and this apparatus was connected to a spectrofluorometer (HORIBA FluoroLog-3) by an optical fibre to obtain a luminescence signal readout (see Supplementary Fig. 13). For the range from $20 \mathrm{ppm}$ to air, standard mixed gases of $\mathrm{O}_{2}$ and $\mathrm{N}_{2}$ from Henan Yuanzheng Special Gas Development Co., Ltd., were used.

\section{Data availability}

Data supporting the findings of this manuscript are available from the corresponding authors upon reasonable request. The X-ray crystallographic coordinates for structures reported in this article have been deposited at the Cambridge Crystallographic Data Centre (CCDC) under deposition number CCDC: $1963529\left(\mathrm{Ag}_{12} \mathrm{bpy}-\mathrm{NH}_{2}\right), 1963530$ $\left(\mathrm{Ag}_{12}\right.$ bpy- $\left.\mathrm{CH}_{3}\right), 1963528\left(\mathrm{Ag}_{12}\right.$ bpy- $\left.\mathrm{CH}_{3} \cdot \mathrm{O}_{2}\right)$.

Received: 6 March 2020; Accepted: 17 June 2020;

Published online: 22 July 2020

\section{References}

1. Nakano, T., Hoshi, K. \& Baba, S. Effect of background gas environment on oxygen incorporation in TiN films deposited using UHV reactive magnetron sputtering. Vacuum 83, 467-469 (2008).

2. Wang, X.-D. \& Wolfbeis, O. S. Optical methods for sensing and imaging oxygen: materials, spectroscopies and applications. Chem. Soc. Rev. 43, 3666-3761 (2014).

3. Wang, X.-D. \& Wolfbeis, O. S. Fiber-optic chemical sensors and biosensors (2008-2012). Anal. Chem. 85, 487-508 (2013).

4. Zhou, Y. et al. Long-lived room-temperature phosphorescence for visual and quantitative detection of oxygen. Angew. Chem. Int. Ed. 58, 12102-12106 (2019).

5. Lehner, P., Staudinger, C., Borisov, S. M. \& Klimant, I. Ultra-sensitive optical oxygen sensors for characterization of nearly anoxic systems. Nat. Commun. $\mathbf{5}$, 4460 (2014).
6. Lu, X. \& Winnik, M. A. Luminescence quenching in polymer/filler nanocomposite films used in oxygen sensors. Chem. Mater. 13, 3449-3463 (2001).

7. Feng, Y., Cheng, J., Zhou, L., Zhou, X. \& Xiang, H. Ratiometric optical oxygen sensing: a review in respect of material design. Analyst 137, 4885-4901 (2012).

8. Liu, S.-Y. et al. Porous $\mathrm{Cu}(\mathrm{I})$ triazolate framework and derived hybrid membrane with exceptionally high sensing efficiency for gaseous oxygen. Adv. Funct. Mater. 24, 5866-5872 (2014).

9. Xu, R. et al. Nanoscale metal-organic frameworks for ratiometric oxygen sensing in live cells. J. Am. Chem. Soc. 138, 2158-2161 (2016).

10. Lan, G. et al. Multifunctional nanoscale metal-organic layers for ratiometric pH and oxygen sensing. J. Am. Chem. Soc. 141, 18964-18969 (2019).

11. Wu, S., Min, H., Shi, W. \& Cheng, P. Multicenter metal-organic frameworkbased ratiometric fluorescent sensors. Adv. Mater. 32, 1805871 (2019).

12. Zhang, K.-Y. et al. Dual-phosphorescent iridium(III) complexes extending oxygen sensing from hypoxia to hyperoxia. J. Am. Chem. Soc. 140, 7827-7834 (2018).

13. Zhao, J., Wu, W., Sun, J. \& Guo, S. Triplet photosensitizers: from molecular design to applications. Chem. Soc. Rev. 42, 5323-5351 (2013).

14. Demchenko, A. P., Tomin, V. I. \& Chou, P.-T. Breaking the Kasha rule for more efficient photochemistry. Chem. Rev. 117, 13353-13381 (2017).

15. McClenaghan, N. D., Leydet, Y., Maubert, B., Indelli, M. T. \& Campagna, S. Excited-state equilibration: a process leading to long-lived metal-to-ligand charge transfer luminescence in supramolecular systems. Coord. Chem. Rev. 249, 1336-1350 (2005).

16. Yaghi, O. M., Kalmutzki, M. J. \& Diercks, C. S. Introduction to Reticular Chemistry: Metal-organic frameworks and covalent organic frameworks. https://doi.org/10.1002/9783527821099 (2019).

17. Pei, X., Bürgi, H.-B., Kapustin, E. A., Liu, Y. \& Yaghi, O. M. Coordinative alignment in the pores of MOFs for the structural determination of N-, S-, and P-containing organic compounds including complex chiral molecules. J. Am. Chem. Soc. 141, 18862-18869 (2019).

18. Xu, W. et al. A metal-organic framework of organic vertices and polyoxometalate linkers as a solid-state electrolyte. J. Am. Chem. Soc. 141, 17522-17526 (2019)

19. Karmakar, A., Samanta, P., Desai, A. V. \& Ghosh, S. K. Guest-responsive metal-organic frameworks as scaffolds for separation and sensing applications. Acc. Chem. Res. 50, 2457-2469 (2017).

20. Lustig, W. P. et al. Metal-organic frameworks: functional luminescent and photonic materials for sensing applications. Chem. Soc. Rev. 46, 3242-3285 (2017).

21. Lan, G. et al. Multifunctional nanoscale metal-organic layers for ratiometric pH and oxygen sensing. J. Am. Chem. Soc. 141, 18964-18969 (2019).

22. An, J., Shade, C. M., Chengelis-Czegan, D. A., Petoud, S. \& Rosi, N. L. Zincadeninate metal-organic framework for aqueous encapsulation and sensitization of near-infrared and visible emitting lanthanide cations. J. Am. Chem. Soc. 133, 1220-1223 (2011).

23. Luo, T.-Y. et al. Luminescence "Turn-On" detection of gossypol using $\mathrm{Ln}^{3}$ +-based metal-organic frameworks and $\mathrm{Ln}^{3+}$ salts. J. Am. Chem. Soc. 142, 2897-2904 (2020).

24. Dou, Z. et al. Luminescent metal-organic framework films as highly sensitive and fast-response oxygen sensors. J. Am. Chem. Soc. 136, 5527-5530 (2014).

25. Cui, Y., Yue, Y., Qian, G. \& Chen, B. Luminescent functional metal-organic frameworks. Chem. Rev. 112, 1126-1162 (2012).

26. Furukawa, H., Cordova, K. E., O’Keeffe, M. \& Yaghi, O. M. The chemistry and applications of metal-organic frameworks. Science 341, 1230444 (2013).

27. Zhang, Y.-M. et al. Luminescent sensors based on metal-organic frameworks. Coord. Chem. Rev. 354, 28-45 (2018).

28. Hu, Z.-C., Benjamin, J. D. \& Li, J. Luminescent metal-organic frameworks for chemical sensing and explosive detection. Chem. Soc. Rev. 43, 5815-5840 (2014).

29. Shimomura, S. et al. Selective sorption of oxygen and nitric oxide by an electron-donating flexible porous coordination polymer. Nat. Chem. 2, 633-637 (2010).

30. Rieth, A. J., Wright, A. M. \& Dincă, M. Kinetic stability of metal-organic frameworks for corrosive and coordinating gas capture. Nat. Rev. Mater. 4, 708-725 (2019).

31. Culp, J. T., Madden, C., Kauffman, K., Shi, F. \& Matranga, C. Screening Hofmann compounds as $\mathrm{CO}_{2}$ sorbents: nontraditional synthetic route to over 40 different pore-functionalized and flexible pillared cyanonickelates. Inorg. Chem. 52, 4205-4216 (2013).

32. Li, J.-R., Kuppler, R. J. \& Zhou, H.-C. Selective gas adsorption and separation in metal-organic frameworks. Chem. Soc. Rev. 38, 1477-1504 (2009).

33. Huang, R.-W. et al. Hypersensitive dual-function luminescence switching of a silver-chalcogenolate cluster-based metal-organic framework. Nat. Chem. 9 , 689-697 (2017)

34. Alhilaly, M. J. et al. Assembly of atomically precise silver nanoclusters into nanocluster-based frameworks. J. Am. Chem. Soc. 141, 9585-9592 (2019). 
35. Wang, Z.-Y. et al. Atomically precise site-specific tailoring and directional assembly of superatomic silver nanoclusters. J. Am. Chem. Soc. 140, 1069-1076 (2018).

36. Huang, R.-W. et al. Tandem silver cluster isomerism and mixed linkers to modulate the photoluminescence of cluster assembled-materials. Angew. Chem. Int. Ed. 57, 8560-8566 (2018).

37. Dong, X.-Y., Huang, H.-L., Wang, J.-Y., Li, H.-Y. \& Zang, S.-Q. A flexible fluorescent SCC-MOF for switchable molecule identification and temperature display. Chem. Mater. 30, 2160-2167 (2018)

38. Wang, J.-Y. et al. A hydrophobic semiconducting metal-organic framework assembled from silver chalcogenide wires. Chem. Commun. 56, 2091-2094 (2020).

39. Jin, R., Pei, Y. \& Tsukuda, T. Controlling nanoparticles with atomic precision. Acc. Chem. Res. 52, 1 (2019).

40. Chakraborty, I. \& Pradeep, T. Atomically precise clusters of noble metals: emerging link between atoms and nanoparticles. Chem. Rev. 117, 8208-8271 (2017).

41. Jin, R.-C., Zeng, C.-J., Zhou, M. \& Chen, Y.-X. Atomically precise colloidal metal nanoclusters and nanoparticles: fundamentals and opportunities. Chem. Rev. 116, 10346-10413 (2016).

42. Kang, X. \& Zhu, M. Tailoring the photoluminescence of atomically precise nanoclusters. Chem. Soc. Rev. 48, 2422-2457 (2019).

43. Han, Z. et al. Ultrastable atomically-precise chiral silver clusters with over $95 \%$ quantum efficiency. Sci. Adv. 6, eaay0107 (2020).

44. Cummings, S. D. \& Eisenberg, R. Tuning the excited-state properties of Platinum (II) diimine dithiolate complexes. J. Am. Chem. Soc. 118, 1949-1960 (1996).

45. You, Y. \& Nam, W. Photofunctional triplet excited states of cyclometalated Ir (III) complexes: beyond electroluminescence. Chem. Soc. Rev. 41, 7061-7084 (2012).

46. Xu, S., Chen, R., Zheng, C. \& Huang, W. Excited state modulation for organic afterglow: materials and applications. Adv. Mater. 28, 9920-9940 (2016).

47. Tao, Y. et al. Resonance-activated spin-flipping for efficient organic ultralong room-temperature phosphorescence. Adv. Mater. 30, 1803856 (2018).

48. Lower, S. K. \& El-Sayed, M. A. The triplet state and molecular electronic processes in organic molecules. Chem. Rev. 66, 199-241 (1966)

49. An, Z. et al. Stabilizing triplet excited states for ultralong organic phosphorescence. Nat. Mater. 14, 685-690 (2015).

50. Zhao, W. et al. Rational molecular design for achieving persistent and efficient pure organic room-temperature phosphorescence. Chem 1, 592-602 (2016).

51. CrysAlis ${ }^{\text {Pro }}$, Version 1.171.36.31. Agilent Technologies Inc., Santa Clara, CA, USA (2012).

52. O. D. Rigaku, CrysAlisPro Software System, Version 1.171.38.41k, Rigaku Coorporation, Oxford, UK (2015).

53. Sheldrick, G. M. A short history of SHELX. Acta Cryst. A 64, 112-122 (2008).

54. Dolomanov, O. V., Bourhis, L. J., Gildea, R. J., Howard, J. A. K. \& Puschmann, H. OLEX2: a complete structure solution, refinement and analysis program. J. Appl. Cryst. 42, 339-341 (2009).

55. Sheldrick, G. M. Crystal structure refinement with SHELXL. Acta Cryst. C. 71, 3-8 (2015)

56. Frisch, M. J. et al. Gaussian, Inc. (Wallingford CT, 2016)

57. Adamo., C. \& Barone, V. Toward reliable density functional methods without adjustable parameters: the PBE0 model. J. Chem. Phys. 110, 6158-6169 (1999).

58. Hariharan, P. C. \& Pople, J. A. The influence of polarization functions on molecular orbital hydrogenation energies. Theor. Chim. Acta 28, 213-222 (1973).

59. Francl, M. M. et al. Self-consistent molecular orbital methods. XXIII. A polarization-type basis set for second-row elements. J. Chem. Phys. 77, 3654-3665 (1982).

60. Hay, P. J. \& Wadt, W. R. Ab initio effective core potentials for molecular calculations. Potentials for the transition metal atoms Sc to Hg. J. Chem. Phys. 82, 270-283 (1985).

61. Hay, P. J. \& Wadt, W. R. Ab initio effective core potentials for molecular calculations. Potentials for main group elements $\mathrm{Na}$ to Bi. J. Chem. Phys. 82, 284-298 (1985).
62. Weigend, F. \& Ahlrichs, R. Balanced basis sets of split valence, triple zeta valence and quadruple zeta valence quality for $\mathrm{H}$ to $\mathrm{Rn}$ : Design and assessment of accuracy. Phys. Chem. Chem. Phys. 7, 3297-3305 (2005).

63. Lu, T. \& Chen, F. W. Multiwfn: a multifunctional wavefunction analyzer. J. Comput. Chem. 33, 580-592 (2012).

64. Neese, F. Software update: the ORCA program system, version 4.0. WIREs Comput. Mol. Sci. 8, e1327 (2018).

65. Kendall, R. A. \& Früchtl, H. A. The impact of the resolution of the identity approximate integral method on modern ab initio algorithm development. Theor. Chem. Acc. 97, 158-163 (1997).

66. Neese, F. An improvement of the resolution of the identity approximation for the formation of the Coulomb matrix. J. Comput. Chem. 24, 1740-1747 (2003).

\section{Acknowledgements}

This work was supported by the National Science Fund for Distinguished Young Scholars (No. 21825106), the National Natural Science Foundation of China (No. 21975065, 21671175), the Program for Science \& Technology Innovation Talents in Universities of Henan Province (164100510005), the Program for Innovative Research Team (in Science and Technology) in Universities of Henan Province (19IRTSTHN022) and Zhengzhou University.

\section{Author contributions}

S.Q.Z. conceived and designed the experiments. X.Y.D., J.S.Y., and Z.H. conducted the synthesis and characterization. Y.S. and P.L. performed the calculations. C.Z. drew pictures in the manuscript. S.Q.Z., X.Y.D., and Z.Y.W. analyzed the experimental results. X.Y.D., S.Q.Z., and T.C.W.M co-wrote the manuscript.

\section{Competing interests}

The authors declare no competing interests.

\section{Additional information}

Supplementary information is available for this paper at https://doi.org/10.1038/s41467020-17200-w.

Correspondence and requests for materials should be addressed to S.-Q.Z.

Peer review information Nature Communications thanks Mei Pan and other, anonymous, reviewer(s) for their contributions to the peer review of this work. Peer review reports are available.

Reprints and permission information is available at http://www.nature.com/reprints

Publisher's note Springer Nature remains neutral with regard to jurisdictional claims in published maps and institutional affiliations.

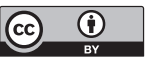

Open Access This article is licensed under a Creative Commons Attribution 4.0 International License, which permits use, sharing, adaptation, distribution and reproduction in any medium or format, as long as you give appropriate credit to the original author(s) and the source, provide a link to the Creative Commons license, and indicate if changes were made. The images or other third party material in this article are included in the article's Creative Commons license, unless indicated otherwise in a credit line to the material. If material is not included in the article's Creative Commons license and your intended use is not permitted by statutory regulation or exceeds the permitted use, you will need to obtain permission directly from the copyright holder. To view a copy of this license, visit http://creativecommons.org/ licenses/by/4.0/.

(C) The Author(s) 2020 